\title{
ARTS-BASED ACTION RESEARCH ON ENHANCING CHILDREN'S CREATIVITY THROUGH AFFECT WITHIN PARTICIPATORY PERFORMANCE ART AND PERFORMANCE PEDAGOGY
}

\author{
Marija GRINIUK \\ Faculty of Art and Design, University of Lapland, Yliopistonkatu 8, 96300 Rovaniemi, Finland
}

Received 19 October 2020; accepted 5 July 2021

\begin{abstract}
This article presents arts-based action research on enhancing children's creativity through affect within participatory performance art and performance pedagogy. The study hypothesis was that children's creativity can be enhanced by affect experienced at a performance site. The purpose of the study was to investigate the impact of children's involvement in artistic performance on their creativity at a performance site. The impact of interactions at the site, the co-participating children, and the involved artists were monitored on a daily basis to collect qualitative data, which were analyzed using a general inductive approach. Objective themes relating to the variables were retrieved from the collected data and assigned codes, concepts, and keywords extracted from photographs, video recordings, and observation notes. The case under investigation was the "Nomadic Radical Academy 2020: The Good, the Bad, and the Art", which built on a pilot event held in 2019. This research concluded that performance art can have a social and creative impact during an art event through children's participation and can be used by performance artists and educators.
\end{abstract}

Keywords: affective ethnography, arts-based action research, children, creativity, participatory performance art, performance pedagogy.

\section{Introduction}

Participatory performance art as social sculpture has been used as a tool for developing the creative potential of participants in art educational contexts since the early 1970s (Moore, 2009). In recent years, arts-based action research (ABAR) has been defined as a method of studying the impact of participatory performance art on the communities involved in art projects (Coghlan \& Brydon-Miller, 2014). ABAR is immersive, and participatory performance art acts as a trigger for dialogical artwork to evolve on site in real time, with the aim of enhancing creativity, creative expression, and interconnectedness between the participants in projects for children and young people. However, tools are lacking to support artists and educators working with performance pedagogy and art education to engage young audiences in projects to enhance their creativity (Cropley, 2014; Chishti \& Jehangir, 2014; Duffy, 2006).

*Corresponding author. E-mail: mgriniuk@ulapland.fi

Copyright (c) 2021 The Author(s). Published by Vilnius Gediminas Technical University

This is an Open Access article distributed under the terms of the Creative Commons Attribution License (http://creativecommons. org/licenses/by/4.0/), which permits unrestricted use, distribution, and reproduction in any medium, provided the original author and source are credited. 
The research question was as follows: How can performance art involving the participation of children have a social and creative impact in real time? This research was significant as a component of the author's work toward her doctoral dissertation and highlighted performance as social and creative sculpture, based on interconnectedness and interactions between artists and children during performative manifestations. The aims of the research were to explore and discuss the connections between affect and creativity during two case-study pilot projects. The objectives of the study were to analyze the two cases of performative manifestations in the pilot projects with participating children and young people and to discuss how performance, co-participants, artists, and the site impacted the involved children and young people in real time.

The object of this study was the traveling education center entitled the "Nomadic Radical Academy" (2019 and 2020), realized as two ABAR pilot projects, based on affective ethnography, hosted by the gallery Meno Parkas in Kaunas, Lithuania. This article is part of an ongoing study on the social impact and interaction design of participatory performance art.

\section{Literature review: creativity}

There is a direct connection between art teaching pedagogies at the elementary school level for children and the capability of children to engage in creative problem-solving in adult life (Chishti \& Jehangir, 2014). Research has shown that individuals who receive art education as children are better at creative problem-solving when they become adults (Chishti \& Jehangir, 2014). It is therefore important to expose children to art practices, as exemplified by the performance art investigated in this research. A paper by Cropley (2014) noted that there is currently little focus on the arts in schools, although performance art not only has a longitudinal impact on a person's creativity, but, during a performance, changes bodily conditions that can be tracked by electroencephalograms (EEGs), which record immediate bodily responses registered as brain waves (Griniuk, 2020b; Gruzelier, 2014). The impact of performance art practices on children's creativity can be of huge pedagogical significance in an educational milieu. Changes within a performing body can be measured by EEGs, and performers can be trained to control certain brain waves (which help enhance creativity) during a performance (Egner \& Gruzelier, 2001, 2003). Bodily conditions have a direct connection to creativity (Egner \& Gruzelier, 2001, 2003); for example, creativity barriers, such as performance anxiety or social anxiety, can be overcome in the process of performing, and EEGs show these changes as a relaxed condition of the body (Gruzelier, 2014). This phenomenon was of huge importance for this research, since the author worked with an EEG to track her bodily conditions during performance art practices (see Figure 1), focusing on the conditions of relaxation and creative immersion in interactions with the audience members (Griniuk, 2020b). In this way, during the "Nomadic Radical Academy 2019" performances, she tracked her creative moments during interactions with the audience members by periodically applying the EEG to record her concentration and relaxation.

The concept of children's creativity for this research was built on Byrge's (2020, p. 9) study, which stated that all children have creative potential. Creativity is inseparable from imagination and, thus, allows people to express themselves through creative actions to change the 


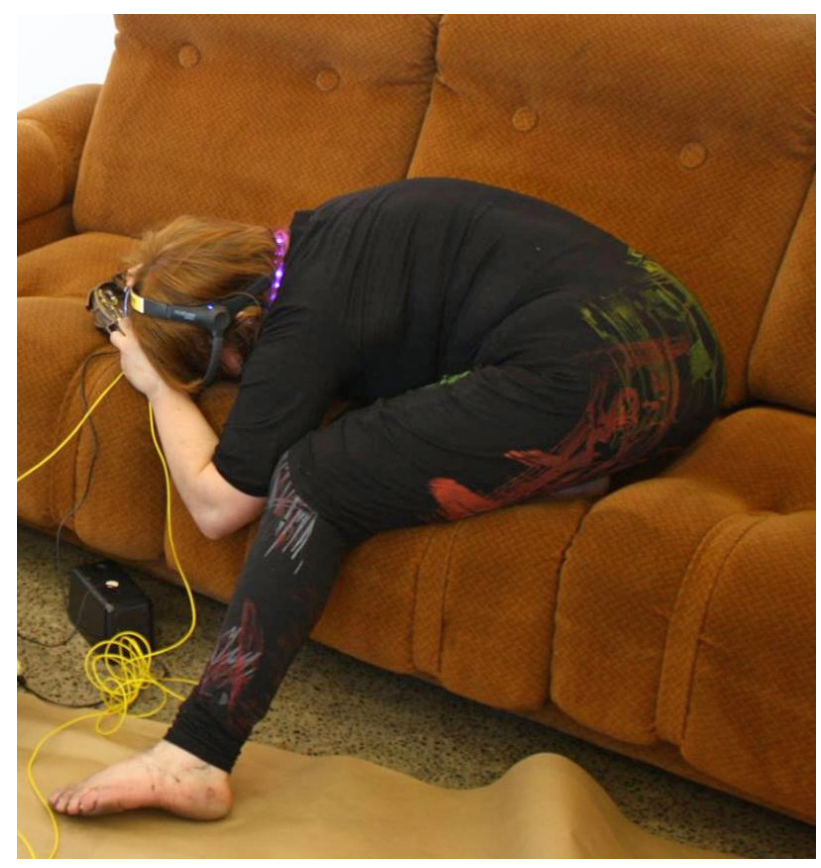

Figure 1. Relaxed condition, tracked by an electroencephalogram (source: Airida Rekštytè, 2019)

environment (Runco \& Albert, 2010, p. 16). Creativity, for some reason, decreases before we reach adulthood (Byrge, 2020, p. 9), perhaps due to institutional power dynamics and children's desire to solve tasks in a specific manner:

"Children's creativity can be encouraged by exposing them to a wide variety of stimulation, providing them opportunities to acquire information and materials and to combine and arrange them, giving children the freedom to ask questions, disagree, experiment, and do things that adults may regard as mistakes, and allocating sufficient time to maintain children's spontaneity" (Majid et al., 2003, p. 68).

Byrge (2020, p. 9) argued that creative potential is partly determined by heredity, early childhood experiences, and education, but it can also be taught; therefore, according to Chishti and Jehangir (2014) and Gruzelier (2014), performance art can be a method for enhancing children's creativity that can have both longitudinal and immediate impacts. The “Nomadic Radical Academy 2019” emphasized vocal and movement-based performance, along with the production of art items from recycled materials. Verbal creativity is at the core of vocal performance, as defined by Gowan (1964). In movement-based performance or during children's interactions with their materials and surroundings, the focus is on motor skills, coordination, and visual and auditory acuity (Gowan, 1964). Sternberg (2020) developed a model called a "straight-A" model to investigate creative processes, which consisted of five variables that influence the creative process in different phases: activators, abilities, amplifiers, audience appeal, and assessment by the audience. As interpreted by Glăveanu (2013), this process involves an actor, action, artifact, audience, and affordances. These five 
concepts were used as themes to analyze the qualitative data gathered during the "Nomadic Radical Academy 2019". This article expands on existing theories and practices regarding performance art as a tool for enhancing children's creativity by discussing the observations of immediate changes within creative performative interactions between the children involved in the nine-day project.

A direct connection between creativity and affect is caused by temporal factors that trigger neurocognitive mechanisms at the site of performance (Eisenberg \& James, 2005). The concept of affect was applied to the participating children in the manner described below. Affect, as described by Katila et al. (2020) and according to Deleuze and Guattari (1987), is experienced by humans when they encounter other (human or non-human) bodies. In participatory performances, affect is experienced when the facilitator encounters the sociomateriality of the performative situation: the participating children, the co-facilitators, the installation in the gallery space, the gallery space, and the materials for activities. Katila et al. (2020) defined affect as changes in bodily conditions during contact with both humans and non-humans, based on the work of Deleuze and Guattari (1987) and Massumi (2002). Katila et al. (2020) described affect as a combination of sensation and energy, which operates in and through relations between bodies.

\section{Methodology: research design}

In the project the "Nomadic Radical Academy 2019", ABAR (Jokela, 2019; Jokela \& Huhmarniemi, 2018) was used to trace the changes in the participating children's creative interactions with each other and with the performance site. ABAR builds on arts-based research (ABR) (Leavy, 2018) and action research; the action research element consists of a series of cycles (Arslan-Ari et al., 2021). ABR was developed in academic contexts and is often applied in research to unite art, sociology, and pedagogy. This interdisciplinary field emerged in the 1970 s and aimed to incorporate the value of aesthetics into the research process (Eisner, 1997). It was further developed into exploratory research, involving creative interpretation and creativity exercises, such as creative writing or visual communication, reflexive drawing and painting, and performativity, among other media. Eisner described the emergence of ABR within pedagogy as follows:

\footnotetext{
"In the early seventies, when I turned to the arts and humanities as sources of research methods and my students and I started to do research using educational connoisseurship and educational criticism, we were expected by most of my colleagues to write extensive justifications for such a personal approach" (1997, p. 5).
}

ABAR takes an exploratory and developmental approach that facilitated cycles of research, in the case of the "Nomadic Radical Academy", from the idea of the pilot project to the artifacts of the performance and the evaluation (Jokela, 2019). A cyclic view of research allows for the possibility of reshaping the research approach, evaluating and developing the research objectives in the process (Jokela, 2019); for example, the study of the "Nomadic Radical Academy" consisted of three cycles: the first cycle focused on research regarding network-building strategies during performance pedagogy projects with children (Griniuk, 2021); the second cycle focused on children's interactive design within art; and the third cycle 
focused on the performance aims of the article, particularly on how to enhance children's creativity through participatory performance. Knowledge is gained through pilot projects (in this case, during the "Nomadic Radical Academy"), and ABAR facilitated an exploratory approach to the study using data gathered through affective ethnography.

Affective ethnography was used as the data collection method (Gherardi, 2019, p. 2), particularly regarding facilitator observation notes compiled when the author was involved as both performer and observer, encountering facilitation and performances by the other contributing artists. The research was conducted from the perspective of the researcher and organizer of the pilot projects within the "Nomadic Radical Academy 2020: The Good, the Bad, and the Art". Gherardi explained affective ethnography as "a style of performative ethnographic process that relies on the researcher's capacity to affect and be affected to produce interpretations that may transform the things that they interpret" $(2019$, p. 2). As an affective ethnographer within the participatory performance, the author was the facilitator and sometimes a participant (participating in activity sessions led by the project's co-facilitators). Praxeology (Long, 2005), as the study of the artistic interaction practices of the co-facilitators of the "Nomadic Radical Academy 2020: The Good, the Bad, and the Art", was conducted by the author. The data for the segments of the praxeology research were observations, notes written in the space of the performance, and reflections after each day's activities, along with detailed photographic and video documentation produced by the author and invited photographers. These data were processed by organizing the data into folders, each of which was labeled with the date and session of the event. A general inductive approach was used to analyze the data gathered during the affective ethnography and praxeology (Thomas, 2006). This approach meant that the raw data were analyzed and evaluated through themes, keywords, and concepts by the researcher (Thomas, 2006). This method of analysis aligned with the ABAR approach and its cyclic structure, with goals being refined and reshaped in each cycle (Thomas, 2006). Based on the structural framework of the study, the data were categorized after each day of the children's creative performance according to the following keywords: actor, action, artifact, audience, and affordances. Further coding was also carried out within each of these five categories.

Regarding research ethics, according to the European Union's General Data Protection Regulation, any personal data must be processed transparently in compliance with the law (Regulations, 2016). Written consent was obtained from parents to photograph and videorecord the involved children for the purposes of this project. The use of an EEG to measure live brain activity during the performance was only used to monitor the performing body of the author as part of the researcher's ongoing $\mathrm{PhD}$ studies at the University of Lapland, Rovaniemi, Finland.

\section{Case study: the "Nomadic Radical Academy" (2019 and 2020)}

The research was based on data concerning children, collected in the form of observation notes and photographs by the author. Other photographic and video material was collected by invited photographers. The ages of the children involved in the two the "Nomadic Radical Academy" projects ranged from 6-13 years. In 2019, the performances lasted on average 


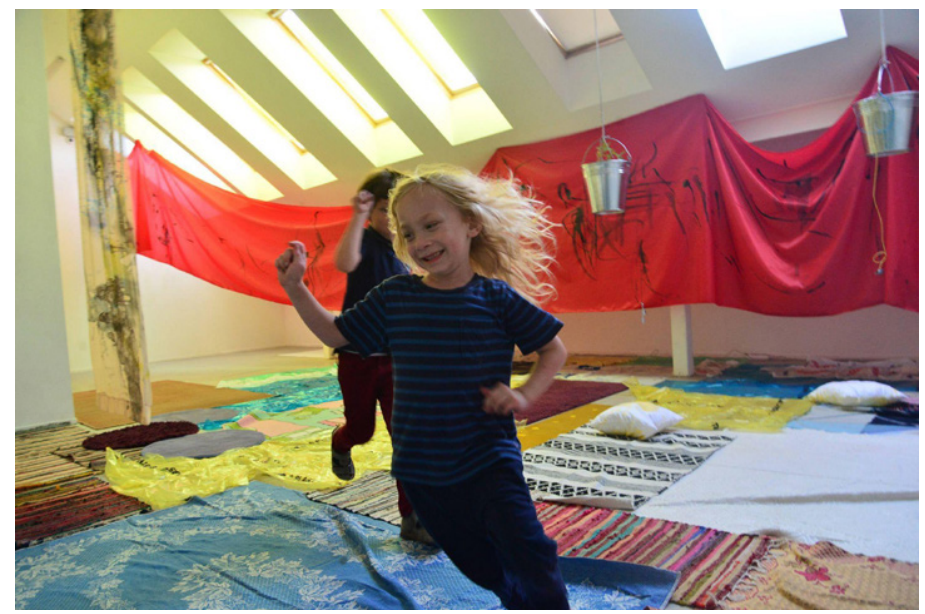

Figure 2. The "Nomadic Radical Academy 2019" (source: Antanas Untidy, 2019)

for 5 hours per day, but in 2020, the duration was 9.5 hours per day. In 2019, 12 children participated (with their family members), and in 2020, 20 children participated without their family members. The children participated voluntarily, and the parents applied for them to attend the event one month before it began. All the involved children and their parents gave consent for the children to be video and photographically recorded during the event.

The "Nomadic Radical Academy 2020: The Good, the Bad, and the Art" built upon the "Nomadic Radical Academy 2019". The international artists involved in the first session of the "Nomadic Radical Academy 2019" were Marija Griniuk, Tue Brisson Mosich, Nanna Ylönen, Marta Gil, Sanna Blennow, Rikke Goldbech, Anne-Louise Knudsen, Anders Werdelin, Adomas Danusevičius, Evelina Šimkute, and Raimondas Binkauskas, among others. The "Nomadic Radical Academy 2020: The Good, the Bad, and the Art" involved contributions by the international artists Griniuk, Julia Kurek, Šimkute, Rait Rosin, Mosich, Julija Rukanskaite, Linda Teikmane, and Kaspar Aus, among others. Both the 2019 and 2020 events were participatory performance events held at gallery Meno Parkas, and they consisted of three days of performances and a two-week exhibition of video documentation after the event in 2019 and nine days of performances in 2020 without the exhibition after the event.

In 2019 ("The Nomadic Radical Academy for Climate Change Awareness at Meno Parkas Gallery" (Echo Gone Wrong, 2020)), the event was split across two of the gallery's floors. The first floor was filled with erected tents (see Figure 3), and the second floor contained a mixed-media installation of used and recycled items (see Figure 2). The gallery space was used to host the invited artists, their artwork, and their performances. In 2019, the participating children attended with their parents. Upon entering the space, the children occupied the tents built from the recycled material and used them during breaks. The performative actions were divided into sessions, and the children and involved grown-ups participated in one- to two-hour sessions with the facilitators (the artists). The themes throughout the entire project were climate change and responsible behavior in nature and one's surroundings. 


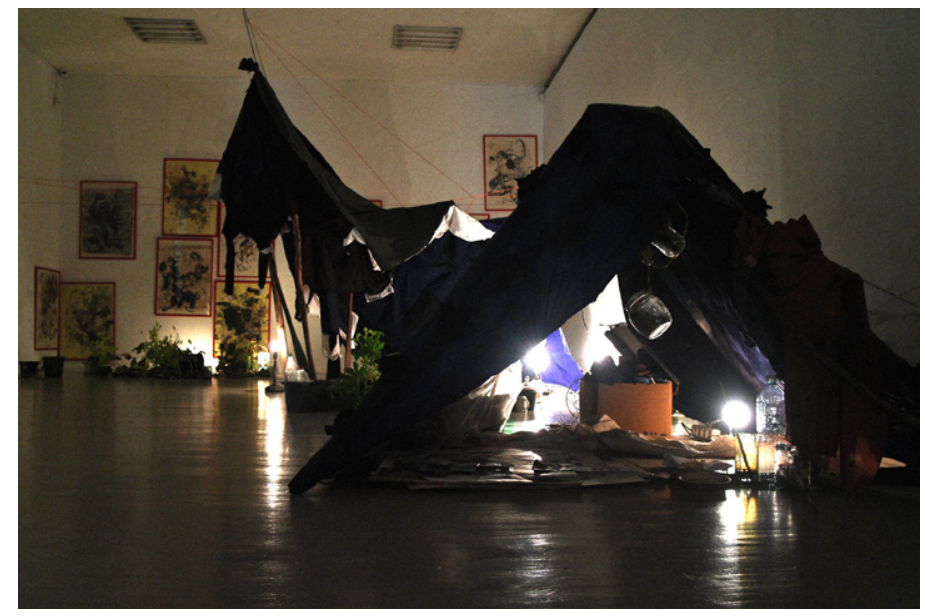

Figure 3. The "Nomadic Radical Academy 2019" (source: Marija Griniuk, 2019)

The case project the "Nomadic Radical Academy 2020: The Good, the Bad, and the Art" was conducted in August, 2020 during the children's summer holidays in the form of a nineday camp. This time, the gallery was entirely taken over by the project. The ground floor and the second floor had been devoted to video documentation and painting and the first floor had been reserved for performative activities. Additionally, performances took place in outdoor areas near the gallery and in the inner yard of the gallery. The performance art program consisted of short-duration performance exercises and live activities. The project was developed for this case study and involved the host facilitator, who performed with the children over the nine days of the event from 8.30 a.m. to 5.00 p.m. Meanwhile, the invited co-facilitators held workshops or involved the children in their own performances, with these activities lasting from 20 minutes to 1.5 hours each (with breaks during the sessions). The children were encouraged to think about the relationship between humans and nature, as well as relationships between humans. They used the gallery space to interact with the facilitators, with each other, with colored paints, and with different materials.

\section{Results}

The results of the ABAR regarding affect and creativity in performance art involving children, as well as their impact on the socio-materiality of the performance site, were based on the following categories: actor, action, artifact, audience, and affordances. Each of these categories was divided according to keywords to facilitate a general inductive approach to the qualitative data analysis.

The main facilitator worked with children solely on the first day of the project and half of the second day to investigate the children's preferences for artistic interactions and to observe the dynamics between the children. Based on these observations, guest co-facilitators were introduced verbally to the group and were given advice on the duration and expected dynamics of the work. The photographic and video materials under the keyword "actor" were 
defined according to subcategories: facilitators, young children aged 6-8 years, children aged 9-13 years, and parents of the children (for the event in 2019).

During the first day, the children seemed unable to concentrate on one activity for more than 30 minutes at a time, and this was the starting point for planning the duration of sessions. They seemed to enjoy longer breaks for social interactions, which was also taken into consideration and appeared to have highly successful outcomes, especially toward the end of the project (after 7 to 9 days), when the children started to use their breaks for their self-organized performative and artistic activities. They occupied the gallery space by self-building tents, roads, and traffic signs, or working in groups of four to five children to fix someone's body to the wall or floor with tape. They made sculptures by applying tape or tape and paper to each other's bodies. The children were divided according to roles, with one child being used as a model and two to three children working with tape or tape and paper.

Some of the participants were creative with their costumes, regularly applying new elements to them as the performance unfolded. Some costumes became usable for the entire project; for example, one participant applied painted silk to enhance her dragon costume with a multi-colored tail, and she used this costume every day during the project. The photographic and video materials under the keyword "action" were categorized according to the following keywords: workshops, performances, and self-organized performances.

These keywords reflected how artifacts from the 2019 performance affected the activities of the participants in 2020, as well as the effects of the artifacts on the performances of the invited artists. The first day of the 2020 event started, among other short performative segments, with the facilitator suggesting that the children create their own costumes, inspired by the video of the 2019 event, during which the children were given a similar task.

The self-built town of tents expanded the idea behind the installation used in the 2019 project. The difference was that in 2019 , the artists built the tents before the performances and only occupied them during the performances. In 2020, the children self-initiated building their town inside the gallery upon the existing installation (see Figure 4).

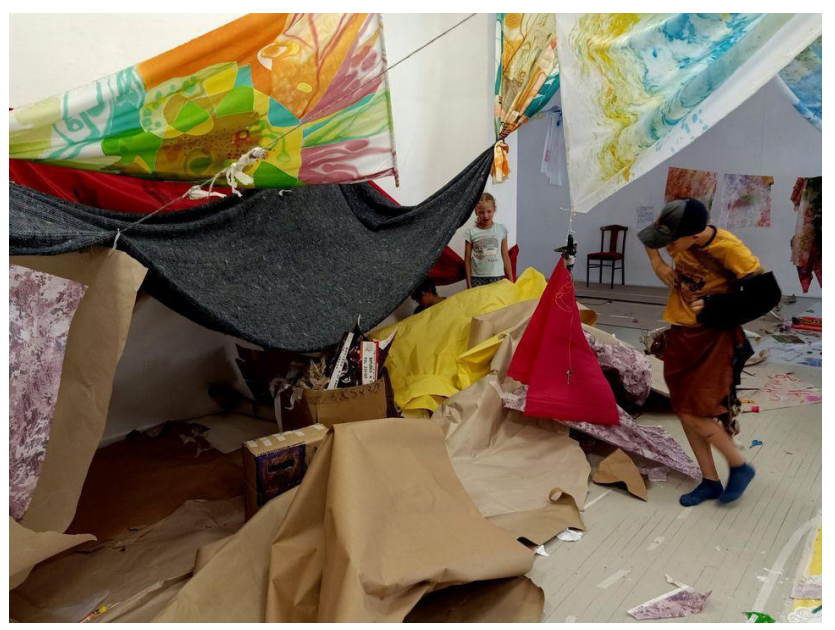

Figure 4. The "Nomadic Radical Academy 2020: The Good, the Bad, and the Art" (source: Raminta Jodikaityte, 2020) 
The children developed their activities based on inspiration from performances or workshops conducted by the artists. A vivid example of such a case was the performance of the artist and scholar Rosin: "Swerve with the good taste food". The artist built a large-sized object (a banana) and interacted with the public spaces by walking in the city of Kaunas with this object. The children were involved in some parts of the artist's performance in the public spaces, following the artist, co-performing, or running and pulling the object along, either alone or in small groups of two to three children. In the days after this performance, the children started to build their own objects with wheels, which they used in their installation in the gallery, sometimes even taking these objects with them to the cafe where they spent their lunch breaks.

The experiments, which were conducted while the author of this paper measured her live brain activity during performances with an EEG device, were also categorized as artifacts. Based on these data, the author was able to reflect on her own bodily condition while engaging in creative performances with the children. Here, "artifacts" referred to the following subcategories: artifacts from 2019 inspiring children, artifacts from other performances inspiring children, artifacts from children's performances, and artifacts from the artists' interactions with the children.

The exposures of the children's performances to various audiences were at the core of these categories, with a specific focus on the impact of enabling children to perform in a public space. The children's creative actions as interventions in the public space were designed to take place within Aus' movement-based three-day performance (multidimensional dance "The Blacksmith Mozart"), for two hours per day (see Figures 4-6). On the first day, the artist focused on determining the children's interest areas, such as by observing their great excitement during movement in a circle where the involved bodies reshaped the form of the circle while moving. This desire for collective embodiment was greater the next day, when, besides movement, the children chose different objects and built structures from them, such as chairs, paper, a ladder, and coal. After observing the children's interest in building chairs

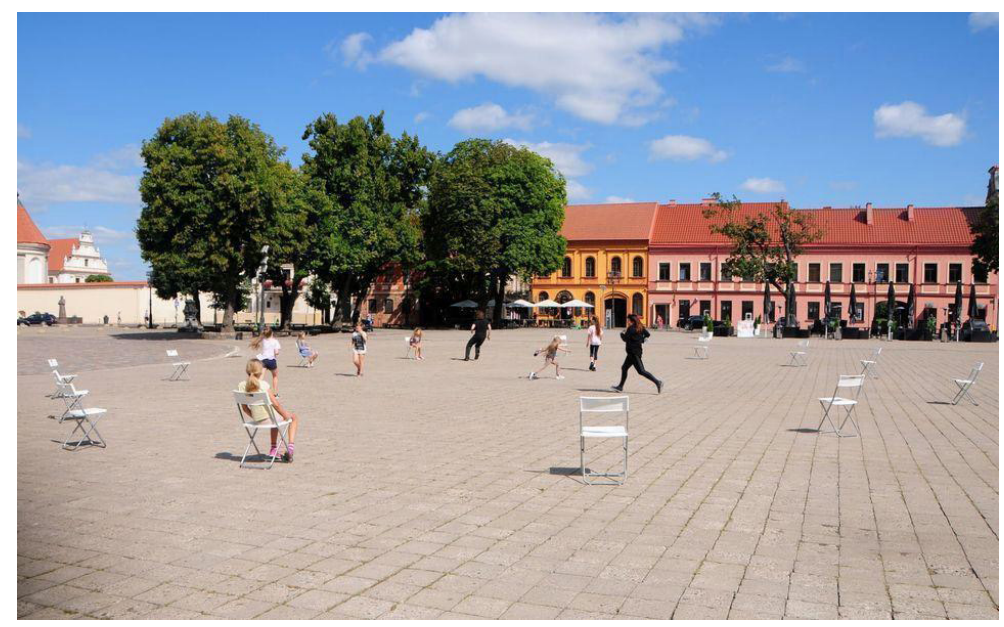

Figure 5. The "Nomadic Radical Academy 2020: The Good, the Bad, and the Art" (source: Raminta Jodikaitytè) 


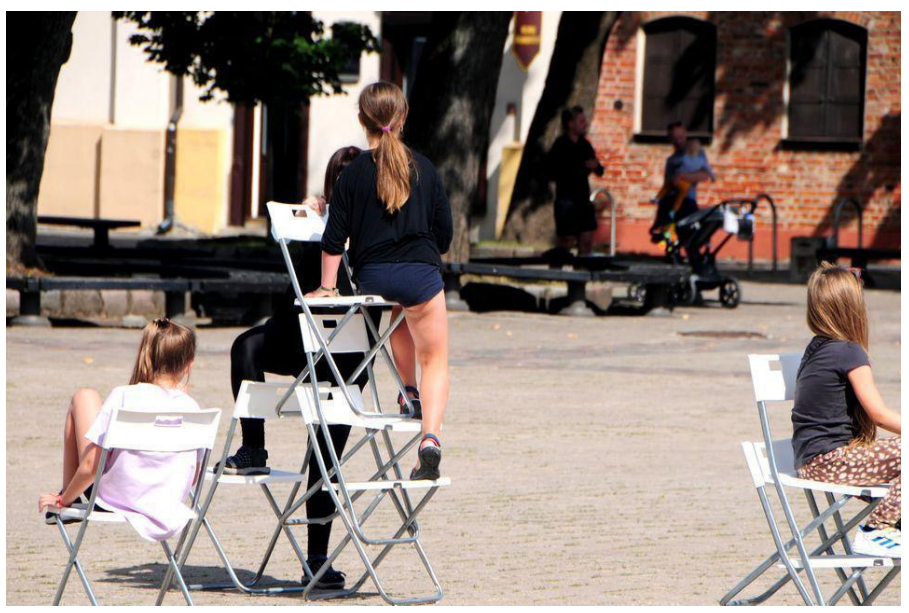

Figure 6. The "Nomadic Radical Academy 2020: The Good, the Bad, and the Art" (source: Raminta Jodikaitytè)

and moving between these constructions, Aus carried out the final session by taking the activity into a public space, with the children taking the chairs outside, forming a large circle, and then moving between and around the chairs. Later, the activity expanded to involve the children in creating different shapes from the chairs in the public space and interacting with them. The chairs were left in place for a further half-hour to allow passersby to observe them and the children to observe the passersby from a distance. This was followed by a discussion about the performative intervention.

The author of this paper gave the children the opportunity to perform in the gallery for a large audience. For the final performance, the children were given gloves, brushes, and colored paint. The gallery floor was covered with plastic, and the facilitator sat on the floor of the gallery, giving the children the opportunity to interact with her at their own height. The facilitator wore a white T-shirt and pants to make the colors more visible. The children interacted with high energy, motivation, and involvement. The facilitator protected her eyes, nose, and mouth with a blindfold. She spoke in a calm tone, explaining how she felt at each moment when the colors were applied. This dialogue seemed to be comforting for the children, and they freely revealed who was applying what color, for example, to an arm or leg. The performance lasted around 20 minutes. Under the category "audiences", the subcategories were outdoor public space, indoor public space, and children as internal audiences.

"Affordances" referred to the materials, surroundings, and objects that acted as triggers for creative action, including photographs, video recordings, and observation notes relating to the children's interaction and co-creation with the objects. This was exemplified by a vignette from the performance by the scholar and artist Kurek observed by Griniuk:

"I call the kids, and we go up to the second floor of the gallery. The sound of the sea and darkness meet us at the entrance to the exhibition hall. The children occupy the chairs, prepared for the audience and the floor. The artist is covered by a fisherman's net, which covers the entire floor of the performance area. A movie of seawater is projected onto the performance area. Plastic bottles are placed under the fisherman's net. The artist starts to move. The movements express the desire to break free of the 
net, and the bottles start to make cracking sounds as the artist's body makes contact with them. I glance at the children, trying to see their reactions in the darkness. A few of us are sitting on the floor, and one girl asks if she can bring up her phone and take a film. The boy moves closer and closer to the net. He puts one of his legs under the net and looks back at me. I smile. In my thoughts, I start to speculate about what will happen if he crawls entirely under the net and starts to co-perform. The artist moves with great intensity, and the cracking sounds from the bottles increase. The boy keeps his leg under the net and touches the net. The projection of the sea touches his leg and hand. The artist breaks free from the net and, after a cycle of interactions with grown-up spectators, invites all the children to join in and step on each of the bottles to make them flat. The kids rush in. Now the cracking sounds fill the entire space for a moment. In the next performance sequence, they take the net and all the bottles downstairs together. They leave them as an item in the exhibition space under the stairs. All the children are helping, and now I am observing the action from behind all grown-ups are passive observers of this collective action. When the net and the bottles are installed in their permanent location, the boy hugs the artist. He tells me later, when we discuss the artwork, that he really wanted to get under the net but was not sure if he was allowed, so he kept only his leg under the projection and the net".

The children seemed to be more open to experimentation and interactions with the materials when they initiated the activity, as described in the following vignette:

\begin{abstract}
"I place long pieces of brown paper on the floor, from one side of the gallery to the other, and the colored paints in bottles. The activity will begin with the children painting with their feet or their hands if they choose to do so. Seven children are taking off their socks and getting ready to start. They make puddles of colors, step into them, and start walking. Someone starts sliding in the puddle of color. More puddles appear, and now a few more children decide to slide. I see that this won't work with only one sheet of paper, so three more pieces appear to allow the children to expand. One participant falls down while sliding, and now his clothes are covered in colors. He is a little worried about his clothes, but I encourage him to continue running around and simply be more careful not to fall, because the floor is wood. Anyway, all who are involved now have colored feet and legs. Someone paints their entire leg on purpose. There are a few places with water provided for cleaning up, and someone starts to wash their legs. Three children remain, sliding and running in the colors. The action continues for more than one hour until all the children are ready to clean themselves".
\end{abstract}

The materials in the category "affordances" were further separated into the following subcategories: performances, materials, interactions between children, and interactions with the performance site. All the described categories and subcategories provided the opportunity to examine the patterns of the children's creative behaviors and to trace transformations between the first and last days of the "Nomadic Radical Academy" project. Here, transformation refers, as described by Schechner (1977), to a change in the behavioral and creative pattern of the involved children's performance.

\title{
Discussion
}

The "Nomadic Radical Academy" project can be defined as performance pedagogy, involving an educator as an actor or a performer, as is usual within pedagogical studies (Lamm Pineau, 1994). The definition of performance pedagogy is based on Fluxus pedagogy and focuses 
on playfulness, a flat structure of interactions, and the active involvement of participating children in decision-making (Griniuk, 2020a), which creates a non-evaluative environment for them (Treffinger et al., 1983). During the workshop sessions of the event, performance pedagogy was used by all the facilitators.

The performance pedagogy project the "Nomadic Radical Academy" can be seen as participatory performance. The children were encouraged to participate in the project, and the events were open for casual gallery audiences to observe. Participatory performance can communicate to participants on one level and to spectators on another level (Bishop, 2011, p. 10). The "Nomadic Radical Academy" constituted a performance according to Schechner's (1977) definition, since it involved a wide spectrum of activities. The participatory performance involved the performing facilitator, the participants, the audience, and the space and time of the performance; the artwork was complete after the transformation within the performance had occurred, as explained by Schechner (1977). The "Nomadic Radical Academy" emphasized this notion of completed artwork by using the last hour of the nine-day event for collective de-installation of the objects in the gallery space by the facilitator and the children.

The facilitator, being involved in the participatory performance in the case of the "Nomadic Radical Academy 2020: The Good, the Bad, and the Art", which involved 95 hours of performance, experienced affect as both an activity and as flux, directly reflecting the ethnographic data collected during the event in real time.

Inviting children into the performance event the "Nomadic Radical Academy" gave them an alternative to their regular school space that focused on affect derived from their surroundings, facilitators, and each other. This space differed from the usual power relations and structures that they were familiar with in school and at home. The adults (i.e., the facilitators) did not focus on direction but instead played along and engaged in the activities with the same spontaneity as the children (Majid et al., 2003). Enhancing children's creativity was aligned with disrupting the power dynamics the children typically experienced. Non-hierarchical relations were gradually achieved as the children adapted to the new space, the facilitators, and the rules of interactions. The "Nomadic Radical Academy" utilized performance and performance pedagogy as tools to facilitate a creative experience for children through affect, enabling them to gradually move from performing in a closed group to performing in public outdoor and indoor spaces (Kozbelt et al., 2010, p. 23). Performance within an art installation in a gallery created a permissive environment that supported imaginative play, whereby creative ideas evolved from the relaxation and enjoyment inherent in play (Kozbelt et al., 2010, p. 26). It also proved possible to gradually achieve this in public spaces with a wider audience present.

The autonomy of the participants, as explained by Kozbelt et al. (2010, p. 20), increased the children's creativity, but the children could only focus on creative action for up to 30 minutes. The facilitators needed to moderate the sessions and shift the children's attention from one activity to another or allow them to take breaks when they lost concentration. The children needed ongoing shifts of focus and affect in the dynamics of the activities, which ranged from vocal to movement-based performance and involved the creation of objects from available materials. The constantly changing activities stimulated the children's interest and involvement. 
This autonomy and shift in power relations were effective in expanding the children's creativity in most cases. The focus was only on inner motivation (E. M. Skaalvik \& S. Skaalvik, 2002) as the key to the autonomy of imagination (Kozbelt et al., 2010). The transformations and role changes over the course of the project were the main interests of the facilitator, since they triggered the creative flow of new ideas and erasure and take-over of the installation space, which made the space dynamic. Performance theories and creativity theories were combined by using performance as a tool to enhance creativity. Liminal spaces, which is where the transformation happens according to Schechner (1977), are spaces of affect that impact creativity (Eisenberg \& James, 2005). In this case, ongoing stimulation and changing performance activities were at the core of maintaining the creative flow and motivation of the group of children (Kozbelt et al., 2010). The product (the installation) was the aesthetic outcome of the children's creative actions, but the performative situation during the creative actions was the focus of the research. While they were carrying out these actions, the children were affected by the materials, each other, and the facilitators, which changed their behavioral and creative patterns; in other words, transformation occurred in a liminal space (Schechner, 1977).

The author of this paper used a NeuroSky EEG device to trace the alpha, beta, and theta waves of her live brain activity (Griniuk, 2020a, 2021) and analyze moments of relaxation and concentration during her interactions with the children. The data were gathered periodically during the performance in 2019 and are part of ongoing research at the University of Lapland (Griniuk, 2020b, 2021).

The transformations of the participating children's creative and behavioral patterns were as follows: During the first two days of their performance, the children were only moderate users of the materials; they had short interactions with each other and needed guidelines and support from the facilitators. From the third to the sixth day, the children were affected by their daily interactions with the invited artists, and they were inspired by the artifacts introduced into the performance space. The children voluntarily took their creative items into a public space and performed with them. The children used the provided materials to extend the scope of their creative actions. From the sixth to the ninth day of the performance, the children, together with the artists, performed in public outdoor and indoor spaces for wider audiences. They self-organized and extended the installation by building large-scale elements inside it. The children extended the facilitated activities both indoors and outdoors and constructed their own creative verbal and visual narratives to support their installations and their performative actions.

\section{Conclusions}

This research defined the major aspects of participatory performance art that enhanced the children's and young people's creativity in the project. The visual and text-based data, analyzed using the categories of actor, action, artifact, audience, and affordances, revealed that the socio-materiality and site of the performance, along with the involved artists and co-participants, impacted the children's creative expressions and affect, transforming the scope of interactions and creative interventions of the children during the performance. The research 
indicates that participation in performance art can strengthen children's inner motivation to be involved in collaborative creative actions. Affect through the impact of the real-time performance was also experienced by the facilitating performance artist, and the artistic manifestation can thus be interpreted as a dialogical affective approach to expanding creative interactions at the site of the performance. It proved possible to foster children's creative actions, thus changing the roles and dynamics in the participant group through participatory performance art. The provided autonomy expanded the children's imagination, the traces and artifacts of which were observed in the gallery space as a reflection of the creative process. The findings of this research are useful for performance artists who are involved in creativityenhancing pedagogical practices with children in institutional contexts.

\section{Acknowledgements}

Thanks for the support and guidance go to the University of Lapland, the Lithuanian Council for Culture, and to Prof Timo Jokela and Dr Maria Huhmarniemi.

\section{References}

Arslan-Ari, I., Ari, F., Grant, M. M., Vasconcelos, L., Tang, H., \& Morris, W. S. (2021). Becoming action researchers: Crafting the curriculum and learning experiences for scholarly practitioners in educational technology. In E. Romero-Hall (Ed.), Research methods in learning design and technology (pp. 78-93). Routledge. https://doi.org/10.4324/9780429260919-6

Bishop, C. (2011). Lecture for creative time's living as form. http://dieklaumichshow.doragarcia.org/ pdfs/Bishop.pdf

Byrge, Ch. (2020). How to teach creativity: A hands-on guide for a holistic development of creative competencies and confidence in education. Business Research \& Business Design.

Chishti, R., \& Jehangir, F. (2014). Positive effects of elementary visual art on problem solving ability in later years of life. FWU Journal of Social Sciences, 8(1), 83-88.

Coghlan, D., \& Brydon-Miller, M. (Eds.). (2014). The SAGE encyclopedia of action research (Vols. 1-2). SAGE Publications, Ltd. https://doi.org/10.4135/9781446294406

Cropley, A. J. (2014). Is there an "Arts Bias" in the Creativity Research Journal? Comment on Glāveanu. Creativity Research Journal, 26(3), 368-371. https://doi.org/10.1080/10400419.2014.929434

Deleuze, G., \& Guattari, F. (1987). A thousand plateaus: Capitalism and schizophrenia. University of Minnesota Press.

Duffy, B. (2006). Supporting early learning. Supporting creativity and imagination in the early years. V. Hurst \& J. Joseph (Series Eds.). Open University Press.

Echo Gone Wrong. (2020). The Nomadic Radical Academy for climate change awareness at Meno Parkas Gallery. https://echogonewrong.com/nomadic-radical-academy-climate-change-awareness-menoparkas-gallery/

Egner, T., \& Gruzelier, J. H. (2003). Ecological validity of neurofeedback: Modulation of slow wave EEG enhances musical performance. NeuroReport, 14(9), 1221-1224.

https://doi.org/10.1097/00001756-200307010-00006

Egner, T., \& Gruzelier, J. H. (2001). Learned self-regulation of EEG frequency components affects attention and event-related brain potentials in humans. NeuroReport, 12(18), 4155-4159.

https://doi.org/10.1097/00001756-200112210-00058 
Eisenberg, J., \& James, K. (2005). The relationship between affect and creativity in organizations: The roles of affect characteristics, neuro-cognitive mechanisms and task type. In N. M. Ashkanasy, W. J. Zerbe, \& Ch. E. J. Härtel (Eds.), Research on emotion in organizations: The effect of affect in organizational settings (Vol. 1, pp. 241-262). Emerald Group Publishing Limited. https://doi.org/10.1016/S1746-9791(05)01110-7

Eisner, E. W. (1997). The promise and perils of alternative forms of data representation, Educational Researcher, 26(6), 4-10. https://doi.org/10.3102/0013189X026006004

Gherardi, S. (2019). Theorizing affective ethnography for organization studies. Organization, 26(6), 741-760. https://doi.org/10.1177/1350508418805285

Glăveanu, V. P. (2013). Rewriting the language of creativity: The five A's framework. Review of General Psychology, 17(1), 69-81. https://doi.org/10.1037/a0029528

Gowan, J. C. (1964). Twenty-Five suggestions for parents of able children. Gifted Child Quarterly, 8(4), 192-193. https://doi.org/10.1177/001698626400800410

Griniuk, M. (2021). Bridging the city: Connecting art, performance design, environment and education. In Society. Integration. Education: Proceedings of the International Scientific Conference, 4, 528-538. https://doi.org/10.17770/sie2021vol4.6412

Griniuk, M. (2020a). Performance pedagogy: Performing Fluxus pedagogy in a contemporary Lithuanian context. Acta Paedagogica Vilnensia, 44, 152-163. https://doi.org/10.15388/ActPaed.44.11

Griniuk, M. (2020b). Reflexive research on performance art documentation through EEG: A visual essay. Research in Arts and Education, 2, 87-97.

Gruzelier, J. H. (2014). EEG-Neurofeedback for optimizing performance. II: Creativity, the performing arts and ecological validity. Neuroscience and Biobehavioral Reviews, 44, 142-158. https://doi.org/10.1016/j.neubiorev.2013.11.004

Katila, S., Kuismin, A., \& Valtonen, A. (2020). Becoming upbeat: Learning the affecto-rhythmic order of organizational practices. Human Relations: Towards the Integration of the Social Sciences, 73(9), 1308-1330. https://doi.org/10.1177/0018726719867753

Kozbelt, A., Beghetto, R. A., \& Runco, M. A. (2010). Theories of creativity. In J. C. Kaufman \& R. J. Sternberg (Eds.), The Cambridge handbook of creativity (pp. 20-47). Cambridge University Press. https://doi.org/10.1017/CBO9780511763205.004

Jokela, T. (2019). Art-based action research for art education in the North. The International Journal of Art and Design Education, 38(3), 599-609. https://doi.org/10.1111/jade.12243

Jokela, T., \& Huhmarniemi, M. (2018). Art-based action research in the development work of arts and art education. In G. Coutts, E. Härkönen, M. Huhmarniemi, \& T. Jokela (Eds.), The lure of Lapland: A handbook of arctic art and design (pp. 9-25). Lapin yliopisto, University of Lapland.

Lamm Pineau, E. (1994). Teaching is performance: Reconceptualizing a problematic metaphor. American Educational Research Journal, 31(1), 3-25. https://doi.org/10.3102/00028312031001003

Leavy, P. (2018). Introduction to arts-based research. In P. Leavy (Ed.), Handbook of arts-based research (pp. 3-21). The Guilford Press.

Long, R. T. (2005). Praxeology: Who needs it. The Journal of Ayn Rand Studies, 6(2), 299-316.

Majid, D. Ab., Tan, A.-G., \& Soh, K.-Ch. (2003). Enhancing children's creativity: An exploratory study on using the internet and SCAMPER as creative writing tools. Korean Journal of Thinking and Problem Solving, 13(2), 67-81.

Massumi, B. (2002). Post-contemporary interventions. Parables for the virtual: Movement, affect, sensation. S. Fish \& J. Jameson (Series Eds.). Duke University Press. https://doi.org/10.1215/9780822383574

Moore, A. W. (2009). A brief genealogy of social sculpture. http://www.joaap.org/webonly/moore.htm

Regulations. (2016). Regulation (EU) 2016/679 of the European Parliament and of the Council of 27 April 2016 on the Protection of Natural Persons with Regard to the Processing of Personal 
Data and on the Free Movement of Such Data, and Repealing Directive 95/46/EC (General Data Protection Regulation). Official Journal of the European Union, 4(5). https://eur-lex.europa.eu/legalcontent/EN/TXT/PDF/?uri=CELEX:32016R0679\&from=EN

Runco, M. A., \& Albert, R. S. (2010). Creativity research: A historical view. In J. C. Kaufman \& R. J. Sternberg (Eds.), The Cambridge handbook of creativity (pp. 3-19). Cambridge University Press. https://doi.org/10.1017/CBO9780511763205.003

Schechner, R. (1977). Essays on Performance Theory, 1970-1976. Drama Book Specialists.

Skaalvik, E. M., \& Skaalvik, S. (2002). Internal and external frames of reference for academic selfconcept. Educational Psychologist, 37(4), 233-244. https://doi.org/10.1207/S15326985EP3704_3

Sternberg, R. J. (2020). Creativity from start to finish: A "Straight-A" model of creative process and its relation to intelligence. Journal of Creative Behavior, 54(2), 229-241. https://doi.org/10.1002/jocb.223

Thomas, D. R. (2006). A general inductive approach for analyzing qualitative evaluation data. American Journal of Evaluation, 27(2), 237-246. https://doi.org/10.1177/1098214005283748

Treffinger, D. J., Isaksen, S. G., \& Firestien, R. L. (1983). Theoretical perspectives on creative learning and its facilitation: An overview. Journal of Creative Behavior, 17(1), 9-17. https://doi.org/10.1002/j.2162-6057.1983.tb00970.x 